\title{
48 shunt catheters impregnated with antibiotics a critical comment on the status of evaluation KA Zweckberger*, KA Unterberg and A Aschoff
}

\author{
Address: University of Heidelberg, Department of Neurosurgery, Im Neuenheimer Feld 400, Heidelberg 69120, Germany \\ Email: KA Zweckberger* - klaus.zweckberger@med.uni-heidelberg.de \\ * Corresponding author
}

\author{
from 50th Annual Meeting of the Society for Research into Hydrocephalus and Spina Bifida \\ Cambridge, UK. 30 August - 2 September 2006 \\ Published: 21 December 2006 \\ Cerebrospinal Fluid Research 2006, 3(SuppI I):S39 doi:I0.I186/1743-8454-3-SI-S39
}

(c) 2006 Zweckberger et al; licensee BioMed Central Ltd.

\section{Background}

The published quote of infections in 108 papers concerning 24.436 shunt-treatments between 1959 and 1993 counts, with a decreasing trend, $8.7 \%$. In three meta-analyses (Haines, Langley, Aschoff 94) a systemic antibiotic prophylaxis, that is standard since 20 years, showed some effect, however, due to low local tissue concentrations and insufficient penetration of the bacterial slime barrier in current studies the improvement of infection rates stagnate at around $8 \%$ and rise up to $21.7 \%$ at children (Vinchon 03). An encouraging step was the development of silicones with antibiotic impregnations (Bayston 89, Kockro 00) in the late eighties. Catheters with 1\% Rifampin and Clindamycin are commercially available since years (Codman BactiSeal ${ }^{\circledR}$ ). Up to 200530.000 sets were sold.

\section{Materials and methods}

In this study we did a retrospective evaluation of the infection rate of BactiSeal shunt-catheters at 48 patients ( 4 of them $<18$ years), who were estimated by the surgeons getting infections with a higher risk, e.g. after systemic inflammations or external CSF drainage.

\section{Results}

Five of 48 (higher-risk)-patients developed a shunt infection in the first year $(10.4 \%)$.

\section{Discussion}

Surprisingly, in the literature we found two prospective randomised studies with 82 patients concerning the use of BactiSeal catheters, only ( $4.9 \%$ infections). In addition we registered one sequential and two retrospective series, all without randomisation; 268 patients showed a mean quote of 2.6\% (no-high risk patients). Inclusively of our own data we summarized 398 BactiSeal-cases with an infection rate of $4.0 \%$ (range $1.4-10.4 \%$ ) that appeared, compared to control groups without antibiotic impregnation, as effective. But generally the statistic power of published evaluations is very poor; they represent $0.27 \%$ of 30.000 sold units, only (status 2005).

\section{Conclusion}

The infection quote of BactiSeal-shunts in patients with higher risks is about 7.5\% (Will 02) resp. 10.4\% (own results). The cumulative quote of impregnated catheters counts $4.0 \%$, that may appear as improved compared to standard experience with infection rates about $8 \%$.

Nevertheless, randomised prospective studies are necessary to prove the effect of antibiotic impregnated catheters especially in patients with a higher risk of infection. 